\title{
Locus of Control: The Mediation Effect between Emotional Stability and Pro-Environmental Behavior
}

\author{
Yi-Te Chiang ${ }^{1}\left(\mathbb{D}\right.$, Wei-Ta Fang ${ }^{1, *(\mathbb{C})}$, Ulas Kaplan ${ }^{2}$ and Eric $\mathrm{Ng}^{3}{ }^{\mathbb{C}}$ \\ 1 Graduate Institute of Environmental Education, National Taiwan Normal University, Taipei 11677, Taiwan; \\ faratajiang@gmail.com \\ 2 Human Development and Learning program, Lesley University, Cambridge, MA 02138, USA; \\ ukaplan@lesley.edu \\ 3 School of Management and Enterprise, University of Southern Queensland, Toowoomba, \\ QLD 4350, Australia; eric.ng@usq.edu.au \\ * Correspondence: wtfang@ntnu.edu.tw; Tel.: +886-2-7734-6558
}

Received: 25 December 2018; Accepted: 1 February 2019; Published: 5 February 2019

check for updates

\begin{abstract}
Locus of control is a crucial factor in pro-environmental behavior. However, studies on pro-environmental behavior investigating the predisposing factors of internal locus of control are limited. Therefore, the objective of this study further explored the predisposing factors of locus of control and revealed that emotional stability may be a predisposing factor for internal locus of control and pro-environmental behavior. A questionnaire survey was conducted in Taiwan $(n=473)$ and the responses were explored using structural equation modeling path analysis. The results revealed that emotional stability can promote pro-environmental behavior through the mediation effect of internal locus of control, indicating that emotional stability is a predisposing factor for locus of control-generated pro-environmental behavior. Thus, the study results indicated that people with higher emotional stability and a stronger internal locus of control are more likely to engage in pro-environmental behavior. Hence, to promote pro-environmental behavior through environmental protection education, people's self-control awareness must be strengthened to enable them to remain calm and peaceful.
\end{abstract}

Keywords: emotional stability; locus of control; pro-environmental behavior; structural equation modeling

\section{Introduction}

Locus of control—the belief about the ability to change a situation through action-is a key dimension of pro-environmental behavior. Peyton and Miller [1] noted that, although knowledge, belief, and attitude of environmental issues, environmental action skills, and other variables can interact with and affect environmental actions, environmental educators should also consider locus of control. They further indicated that even if individuals possess the necessary environmental knowledge, values, and action skills, they will not engage in environmental actions if they cannot implement changes through their behavior. Hence, locus of control is likely to be critical for pro-environmental behavior. Consistently, many studies have revealed a link between locus of control and pro-environmental behavior [2-17]. In particular, the model of responsible environmental behavior (REB) developed by Hines, Hungerford, and Tomera [2], which incorporates the influence of locus of control, has been widely applied in studies of environmental education and pro-environmental behavior.

However, locus of control is a rather abstract concept of personality psychology; the specific factors that lead to its emergence and whether these factors also affect pro-environmental behavior remain unknown. Few empirical studies have investigated these issues. Therefore, the purpose of 
the current study is to identify the predisposing factors of locus of control, perform exploratory and confirmatory analyses, and describe the impact path.

\subsection{Locus of Control}

Locus of control was first proposed by Rotter [18], and it has been a key factor in the exploration of personality and behavior. Locus of control refers to people's interpretation of responsibility for events. It represents generalized expectancies that events in one's life are under or outside of one's control. In the context of social learning theory, Rotter [18] claims that locus of control describes an individual's ability to determine the outcome of their behavior. In particular, people with a stronger internal locus of control tend to believe that they have control over their lives and therefore attribute the outcomes of events to their own self-control behavior [18,19]. Furthermore, they believe that the outcome of an action is the result of their own accomplishment, which is achieved through their own efforts [20]. Such individuals are more likely to believe that an outcome arises from their own self-control [21], and they tend to assign praise or blame to their own ability [22].

In contrast, people who attribute responsibility to external factors tend to believe that their outcomes in life are determined by uncontrollable opportunities, fate, or environmental factors $[2,18]$. People with a stronger external locus of control do not attempt to implement changes on the basis of their own expectations [1]. Instead, they tend to believe that life events are beyond their control [21]: they either praise or blame external factors after an outcome arises [22].

Peyton and Miller propose roles that locus of control plays in environmental actions in addition to affecting pro-environmental behavior [1]: Compared with individuals possessing external locus of control, those with internal locus of control (1) tend to be initiators of social reform and social movements, and they positively attempt to control the environment; (2) tend to seek knowledge and information more positively, which is a crucial ability for solving environmental problems; (3) employ information more effectively; and (4) are more able to resist subtle manipulations and inhibit the dissemination of biased and erroneous information. (5) Individuals with internal locus of control are able to delay gratification to obtain more substantial and insightful long-term benefits. (6) Compared with individuals possessing external locus of control, those with internal locus of control believe that skills rather than opportunity affect outcomes. Therefore, they are more willing to perform effort to achieve the desired outcome. (7) Internal locus of control indicates that an individual is more likely to change their self-concept and assume responsibility. Peyton and Miller mentioned that locus of control is affected by family origin, race, social class, and psychological age [1]. Thus, because locus of control is a particularly abstract concept, predisposing factors are likely to affect its formation. Therefore, the aim of the current study is to identify factors linked to the path of pro-environmental behavior. In addition to exploring locus of control, we investigated whether predisposing factors can be inferred through observation of individuals' pro-environmental behavior. Thus, this study further explored the predisposing factors of locus of control to fill in the research gap and resolve problems that are not easily observed or predicted in the path from locus of control to pro-environmental behavior.

\subsection{Emotional Stability and Neuroticism}

A review of previous studies indicate that the emotion-related personality trait variables can facilitate the understanding of factors contributing to the formation of locus of control. According to Smith [23], emotions are spiritual actions and physical responses derived from human evolution that can be categorized into 150 different types. The ability to accurately detect, control, and manage emotions is associated with high stress resistance [24], sound work performance [25], and leadership [26]. Some studies have indicated that locus of control is associated with emotional stability and neuroticism $[27,28]$. Judge et al. further revealed that locus of control and neuroticism are the most widely studied personality trait concepts in psychology [29]. In addition, several studies have demonstrated that locus of control and anxiety are negatively correlated [30-32]. In other words, 
the higher the anxiety score, the greater the tendency towards internal locus of control. Anxiety is classified as a major element in neuroticism [33].

Emotional stability is a major psychological characteristic that is generated when people encounter difficulties or stress in daily life, and it has a stabilizing effect [24,34]. Furthermore, it is one of the big five personality traits proposed by $\mathrm{McCrae}$ and Costa [35]. Individuals with high emotional stability are regarded as calm, relaxed, safe, and comfortable. They are patient, self-contentment, deliberative, unenvious, strong-minded, and objective [35-37]. Although emotional stability is an emotion-based characteristic that is considered unrelated to cognition-based values [38], studies have shown that among the big five personality traits, it is a key factor affecting pro-environmental behavior [39-44]. Previous studies reveal that personality traits may change because of a person's life learning experience, and as a result become more cautious, reliable, and knowledgeable [45]. Pro-environmental behavior can also be affected by norms and well-educated etiquettes since intense external influences can help form humans' normative belief, whereas better educational situations may be related to factors such as "herd effect" and "consequence awareness" [45].

Conversely, other studies have suggested that neuroticism is the cause of pro-environmental behavior. Neuroticism is an important negative predictor of mental health [46] and includes sensitivity, stubbornness, weakness, lack of patience, impulsiveness, high subjectivity, emotional tendencies, irritability, nervousness, suspicion, envy, self-pity, lack of trust, insecurity, and often feeling fretful and worried [35-37]. Neuroticism is often associated with anxiety and self-doubt [47] as well as with guilt, pessimism, and low self-esteem tendencies [48,49]. In addition, neurotic individuals are prone to excessive emotional responses at work and are unable to effectively regulate negative emotions [50]. However, people with a high degree of neuroticism sometimes exhibit emotions that are not completely negative. Fundamentally, in an atmosphere of negative emotions, these individuals are sensitive, sentimental, and display power-saving behaviors [43]. Their concern for future environmental conditions is established through environmental awareness [51], giving rise to pro-environmental behaviors as well as concern, sensitivity, and uneasiness regarding the future environmental conditions [52,53]. Based on previous studies, we posit that emotional stability and neuroticism are self-expressions of the external environment. To generate environmentally friendly behaviors, these traits require mediating factors, and both are regarded as emotional motives. The effects of emotional stability and neuroticism on pro-environmental behavior remain disputed among scholars. Hence, more rigorous research is to be conducted to gain further insights. In this study, emotional stability and neuroticism have been adopted as two more easily observed explicit personality traits to reflect locus of control, which is less easily observed. Therefore, this study aims to investigate the correlations between emotional stability and neuroticism, locus of control, and pro-environmental behavior.

\subsection{Proposed Framework and Hypotheses}

This research has adopted the emotional stability and REB models of the big five personality traits to explore the correlations between the variables, namely (1) internal locus of control, emotional stability, and pro-environmental behavior (as shown in Figure 1) and (2) external locus of control, neuroticism, and pro-environmental behavior (as shown in Figure 2). The proposal to investigate two research models separately in this study is mainly because a single model is not necessarily able to clearly explain the complex causality of human behaviors. Thus, the use of two separate models that focus on the specific path relationships between the variables is intended to provide a better clarity and distinct understanding of such complicated human behaviors. Furthermore, previous studies have also investigated internal and external locus of control separately in various contexts such as health behaviors [54], pro-environmental behaviors [55,56], cyberloafing behaviors [57], and social anxiety [58]. 


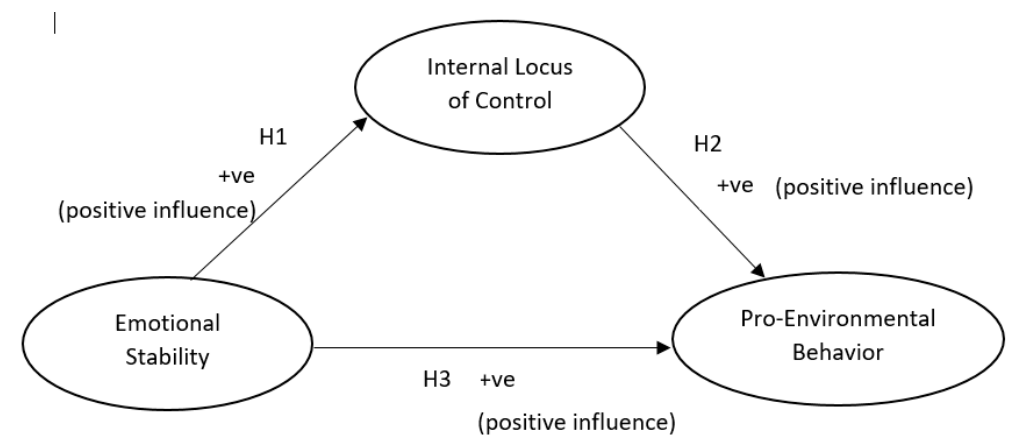

Figure 1. Proposed research framework for internal local control (ILoC), emotional stability (ES), and pro-environmental behavior (PEB).

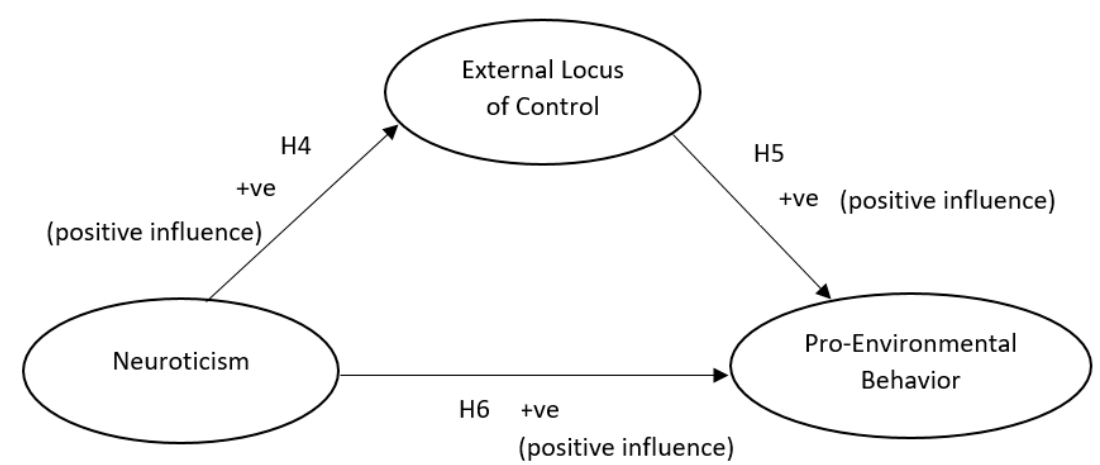

Figure 2. Alternative model for external local control (ELoC), neuroticism (N) and pro-environmental behavior (PEB).

Based on the extant literature, the following hypotheses are proposed to be examined.

H1. Emotional stability positively influences internal locus of control [27-29].

H2. Internal locus of control positively influences pro-environmental behavior [2-17].

H3. Emotional stability positively influences pro-environmental behavior [39-44].

H4. Neuroticism positively influences external locus of control [30,31].

H5. Neuroticism positively influences external locus of control [30,31], and positively influences pro-environmental behavior $[43,52,59]$. The second model assumes, therefore, external locus of control positively influences pro-environmental behavior.

H6. Neuroticism positively influences pro-environmental behavior [43,52,59].

\section{Materials and Methods}

\subsection{Participants and Procedure}

Therefore, in order to verify the aforementioned theoretical framework we conducted an online questionnaire on the Internet for the Taiwan Environmental Protection Organization to collect samples that exceeded the estimated parameters detected by five times in sampling frame. Theories and hypotheses were proposed on the basis of previous studies, and research verification was performed using structural equation modeling (SEM). The National Taiwan Normal University Research Ethics Committee confirmed that our study does not fall within the scope of the Human Subjects Research Act in Taiwan, Republic of China (ROC). This committee approved the study protocol (201707HS001) and agreed with active informed consent by the all participants with the option to opt out of this research in all sampling process. 
Nonprobability sampling was employed in this study. Most respondents participated after passing the public recruitment process and the corresponding snowball system. Many respondents not only completed their own questionnaire but were also willing to distribute additional questionnaires. In total, 500 questionnaires were distributed and 473 valid responses were returned.

\subsection{Measures}

This study has adopted the big five personality traits that were proposed by Goldberg [60] and Saucier [36] with 100 characteristics as their bases and constituting factors, to test the participants' emotional stability (or neuroticism). The emotional stability traits were extracted from these studies and compiled into similar (i.e., positive or negative) traits. Five statements were selected to be included in the questionnaire, namely "I'm touchy $(R)$ ", "I'm insecure (R)", "I'm stubborn (R)", "I'm envious $(\mathrm{R})$ ", and "I'm fretful (R)." A five-point Likert scale (i.e., 1 = strongly disagree; 2 = disagree; 3 = neutral; $4=$ agree; $5=$ strongly agree) was used as a measurement to the respondents' answers about these personality traits.

The statement "I am only one person, I can't make a difference to the environment (R)" was extracted from Fielding and Head to measure locus of control [12]. Moreover, the factors among participants' responses that were considered to influence pro-environmental behavior included "I don't have time (R)" [12] and "I'm more concerned with saving money (R)" [12]. Therefore, these statements were adopted for the current study, in which the participants' locus of control toward the environment was assessed using a five-point Likert scale (i.e., 1 = strongly disagree; 2 = disagree; 3 = neutral; $4=$ agree; 5 = strongly agree).

Statements about pro-environmental behavior were adopted from The Belgrade Charter [61], Fielding and Head [12], and Hungerford [62]. There were four PEB statements included in the questionnaire, namely "I will regard to its consequences on society and on the resources available" [61], "I am concerned with the behaviors of environmental protection groups", "I will persuade friends and relatives for environmental action" [62], and "Write a letter or sign a petition that is about protecting the environment" [12]. The participants' attitude toward the environment was measured using a five-point Likert scale (i.e., $1=$ strongly disagree; $2=$ disagree; $3=$ neutral; $4=$ agree; $5=$ strongly agree).

The Statistical Package for the Social Sciences (SPSS v.23) was used for analysis in this study. The reliability analysis confirmed that the questionnaires achieved a Cronbach's $\alpha$ on the following; emotional stability (0.695), neuroticism (0.695), internal locus of control (0.793), external locus of control (0.793), and pro-environmental behavior (0.824), indicating reliability. Additionally, LISREL9.2 [63] was used to analyze the research hypotheses and measurement dimensions to establish a structural equation model and verify the overall and internal fit of the hypothetical research framework. Maximum likelihood estimation was applied to estimate the model parameters. Various fit indices were used as determination bases to test the overall model fit. A goodness-of-fit index (GFI), a comparative fit index (CFI), and a non-normed fit index (NNFI) of $>0.90$ indicated acceptable goodness of fit; a root mean square error approximation (RMSEA) of $<0.080$ indicated acceptable goodness of fit; and a normed chi-squared value of greater than 3 was preferred.

\section{Results}

\subsection{Descriptive Findings}

A total of 473 valid questionnaires were returned. The findings indicated that there were more females (58.4\%) than males (41.6\%) responded to the questionnaire survey. Majority of the participants were university or college graduates $(58.7 \%)$, and this was followed by masters and above $(36 \%)$, as well as high school and below (5.3\%). Most of the participants were aged 21 to 30 years $(65 \%)$, and this was followed by the ages of 31 to 40 years (18\%) and 41 to 50 years $(9.3 \%)$, respectively. Tables 1 and 2 provide a brief summary of the participants' educational background and age groups. 
Table 1. Descriptive statistics on participants' educational backgrounds.

\begin{tabular}{ccccc}
\hline \multirow{2}{*}{ Gender } & \multicolumn{3}{c}{ Educational Background } & \multirow{2}{*}{ Total } \\
\cline { 2 - 4 } & $\begin{array}{c}\text { High School Graduates } \\
\text { and below }\end{array}$ & $\begin{array}{c}\text { University or } \\
\text { College Graduates }\end{array}$ & Masters and above & \\
\hline Males & $8(4.06 \%)$ & $115(58.38 \%)$ & $74(37.56 \%)$ & 197 \\
Females & $17(6.16 \%)$ & $163(59.06 \%)$ & $96(34.78 \%)$ & 276 \\
Total & $25(5.29 \%)$ & $278(58.73 \%)$ & $170(35.94 \%)$ & 473 \\
\hline
\end{tabular}

Table 2. Descriptive statistics on participants' age groups.

\begin{tabular}{|c|c|c|c|c|c|c|}
\hline \multirow{2}{*}{ Gender } & \multicolumn{5}{|c|}{ Age Group } & \multirow{2}{*}{ Total } \\
\hline & Under 20 Years Old & 21-30 Years Old & 31-40 Years Old & 41-50 Years Old & Over 50 Years Old & \\
\hline Males & $4(2.03 \%)$ & $134(68.02 \%)$ & $36(18.27 \%)$ & $19(4.06 \%)$ & $4(2.03 \%)$ & 197 \\
\hline Females & $7(2.54 \%)$ & $173(62.68 \%)$ & $49(17.75 \%)$ & $25(9.06 \%)$ & $22(7.97 \%)$ & 276 \\
\hline Total & $11(2.33 \%)$ & $307(64.90 \%)$ & $85(17.97 \%)$ & $44(9.30 \%)$ & $26(5.50 \%)$ & 473 \\
\hline
\end{tabular}

Findings for the emotional stability items were presented in Table 3. Among the five emotional stability items "I'm insecure. (R)" and "I'm envious. (R)" had the highest mean score, and this was followed by "I'm fretful (R)", "I'm fretful (R)", and "I'm stubborn (R)". The results indicated an internal consistency reliability measurement with the Cronbach's $\alpha$ value of 0.695 for the emotional stability items. However, the "I'm touchy $(\mathrm{R})$ " and "I'm stubborn (R)" items had been removed from subsequent analysis as their individual factor loadings was less than 0.5 , which did not meet the minimum threshold factor loadings requirement [64].

Table 3. Descriptive statistics for emotional stability items.

\begin{tabular}{lll}
\hline Emotional Stability & Mean & SD \\
\hline ES1. I'm touchy. (R) & 2.90 & 0.96 \\
ES2. I'm insecure. (R) & 3.56 & 0.93 \\
ES3. I'm stubborn. (R) & 2.61 & 0.83 \\
ES4. I'm envious. (R) & 3.53 & 1.00 \\
ES5. I'm fretful. (R) & 2.75 & 0.95 \\
Overall emotional stability & 3.07 & 0.63 \\
\hline
\end{tabular}

Findings for the neuroticism items are presented in Table 4. Among the five neuroticism items, "I'm fretful." and "I'm stubborn." had the highest mean score, and this was followed by "I'm touchy", "I'm envious", and "I'm insecure." The results indicated an internal consistency reliability measurement with the Cronbach's $\alpha$ value of 0.695 for the emotional stability items. However, there were two items ("I'm touchy $(\mathrm{R})$ " and "I'm stubborn (R)") removed from the subsequent analysis since their individual factor loadings was less than 0.5 , and thus not meeting the minimum threshold requirement for factor loadings [64].

Table 4. Descriptive statistics for neuroticism items.

\begin{tabular}{lll}
\hline Neuroticism & Mean & SD \\
\hline N1. I'm touchy & 3.10 & 0.96 \\
N2. I'm insecure. & 2.19 & 1.01 \\
N3. I'm stubborn & 3.39 & 0.83 \\
N4. I'm envious. & 2.25 & 1.12 \\
N5. I'm fretful. & 3.41 & 1.17 \\
Overall neuroticism & 2.93 & 0.63 \\
\hline
\end{tabular}

Results (see Table 5) indicated that there were three internal locus of control items; "I am only one person, I can't make a difference to the environment (R)" and "I'm more concerned with saving money $(\mathrm{R})$ " received the highest and lowest mean scores, respectively. Other items also included "I don't have 
time (R)". The Cronbach's $\alpha$ value of 0.793 suggested internal consistency for the internal locus of control items.

Table 5. Descriptive statistics for internal locus of control items.

\begin{tabular}{lcc}
\hline Internal Locus of Control & Mean & SD \\
\hline ILoC1. I am only one person, I can't make a difference to the environment. (R) & 4.16 & 0.83 \\
ILoC2. I don't have time. (R) & 4.01 & 0.93 \\
ILoC3. I'm more concerned with saving money. (R) & 4.02 & 0.83 \\
Overall locus of control & 4.06 & 0.73 \\
\hline
\end{tabular}

Results (see Table 6) indicated that there were three external locus of control items; "I don't have time" and "I'm more concerned with saving money" received the highest and lowest mean scores, respectively. Other items also included "I am only one person, I can't make a difference to the environment." The Cronbach's $\alpha$ value of 0.793 suggested internal consistency for the external locus of control items.

Table 6. Descriptive statistics for external locus of control items.

\begin{tabular}{lcc}
\hline External Locus of Control & Mean & SD \\
\hline ELoC1. I am only one person, I can't make a difference to the environment. & 1.69 & 0.76 \\
ELoC2. I don't have time. & 1.85 & 0.92 \\
ELoC3. I'm more concerned with saving money. & 1.79 & 0.76 \\
Overall locus of control & 1.69 & 0.63 \\
\hline
\end{tabular}

Findings (see Table 7) also revealed that there were four items about pro-environmental behavior, and of which "I will regard to its consequences on society and on the resources available." had the highest mean score. This was followed by "I am concerend with the behaviors of enviornmental protection group", "I will persuade friends and relatives for environmental action", and "Write a letter or sign a petition that is about protecting the environment", respectively. The internal consistency reliability for the pro-environmental behavior items was measured with the Cronbach's $\alpha$ value of 0.824 .

Table 7. Descriptive statistics for pro-environmental behavior items.

\begin{tabular}{lcc}
\hline Pro-Environmental Behavior & Mean & SD \\
\hline PEB1. I will regard to its consequences on society and on the resources available. & 3.55 & 0.76 \\
PEB2. I am concerend with the behaviors of enviornmental protection groups. & 3.18 & 1.03 \\
PEB3. I will persuade friends and relatives for environmental action. & 3.03 & 1.03 \\
PEB4. Write a letter or sign a petition that is about protecting the environment. & 2.68 & 1.12 \\
Overall pro-environmental behavior & 3.11 & 0.80 \\
\hline
\end{tabular}

\subsection{Correlation Analysis}

According to the correlation analysis (see Table 8), the relationship between emotional stability and internal locus of control $(r=0.316)$ was the strongest. Findings also revealed low correlations between internal locus of control and pro-environmental behavior $(r=0.237)$, emotional stability, and pro-environmental behavior $(r=0.096)$. Thus, all three dimensions in this study were correlated. 
Table 8. Pearson correlation matrix.

\begin{tabular}{cccccc}
\hline \multicolumn{1}{c}{ ES } & $\mathbf{N}$ & ILoC & ELoC & PEB \\
\hline ES & 1.000 & & & & \\
$\mathbf{N}$ & $-1.000^{* * *}$ & 1.000 & & & \\
ILoC & $0.316^{* * *}$ & $-0.316^{* *}$ & 1.000 & & \\
ELoC & $-0.316^{* * *}$ & $0.316^{*}$ & $-1.000^{* *}$ & 1.000 & \\
PEB & $0.096^{*}$ & $-0.096^{*}$ & $0.237^{* * *}$ & $-0.237^{* * *}$ & 1.000 \\
\hline${ }^{* * *}: p<0.001$, two-tailed test; ${ }^{* *}: p<0.01$, two-tailed test; $*: p<0.05$, two-tailed test.
\end{tabular}

\subsection{Hypothesis Testing}

LISREL9.2 [63] was used to analyze the research hypotheses and measurement dimensions to establish a structural equation model that verify the overall and internal fit of the hypothetical research framework. Maximum likelihood estimation was applied to estimate the model parameters. Various fit indices were used as determination bases to test the overall model fit. A goodness-of-fit index (GFI), a comparative fit index (CFI), and a non-normed fit index (NNFI) of $>0.90$ indicated acceptable goodness of fit; a root mean square error approximation (RMSEA) of $<0.080$ indicated acceptable goodness of fit; and a normed chi-square of greater than 3 was preferred.

In addition, the verification process revealed that among the emotional stability and neuroticism variables, the factor loading of four items (i.e., ES1, ES3, N1, and N3) was less than 0.5, and were subsequently removed from further analysis since they did not meet the minimum required threshold of the factor loadings [64]. Pearson correlation analysis (see Tables 9 and 10) was conducted to determine the correlation between emotional stability and internal locus of control, and neuroticism and external locus of control. The results suggested that ES1 (touching) and ES3 (stubborn) items had negligible significant correlation with two of the three internal locus of control items, and the analysis results of N1 and N3 with external locus of control were similar. This confirmed that ES1, ES3, N1, and N3 items were insignificant to internal and external locus of control respectively.

Table 9. Pearson correlation matrix-Emotional stability and internal locus of control.

\begin{tabular}{|c|c|c|c|c|c|c|c|c|}
\hline & ES1 & ES2 & ES3 & ES4 & ES5 & ILoC1 & ILoC2 & ILoC3 \\
\hline ES1 & 1.000 & & & & & & & \\
\hline ES2 & $0.284^{* * *}$ & 1.000 & & & & & & \\
\hline ES3 & $0.226^{* * *}$ & $0.248^{* * *}$ & 1.000 & & & & & \\
\hline ES4 & $0.333^{* * *}$ & $0.336^{* * *}$ & $0.144^{* *}$ & 1.000 & & & & \\
\hline ES5 & $0.581^{* * *}$ & $0.297^{* * *}$ & $0.224^{* * *}$ & $0.413^{* * *}$ & 1.000 & & & \\
\hline ILoC1 & 0.022 & $0.143^{* *}$ & 0.082 & $0.191 * * *$ & $0.147^{* *}$ & 1.000 & & \\
\hline ILoC2 & 0.046 & $0.208^{* * *}$ & 0.119 ** & $0.253^{* * *}$ & $0.184^{* * *}$ & $0.575^{* * *}$ & 1.000 & \\
\hline ILoC3 & $0.119^{* *}$ & $0.216^{* * *}$ & 0.066 & $0.225^{* * *}$ & $0.230^{* * *}$ & $0.498^{* * *}$ & $0.612 * * *$ & 1.000 \\
\hline
\end{tabular}

Table 10. Pearson correlation matrix-Neuroticism and external locus of control.

\begin{tabular}{|c|c|c|c|c|c|c|c|c|}
\hline & N1 & N2 & N3 & N4 & N5 & ELoC1 & ELoC2 & ELoC3 \\
\hline N1 & 1.000 & & & & & & & \\
\hline N2 & $0.284^{* * *}$ & 1.000 & & & & & & \\
\hline N3 & $0.226^{* * *}$ & $0.248^{* * *}$ & 1.000 & & & & & \\
\hline N4 & $0.333^{* * *}$ & $0.336^{* * *}$ & $0.144^{* *}$ & 1.000 & & & & \\
\hline N5 & $0.581^{* * *}$ & $0.297^{* * *}$ & $0.224^{* * *}$ & $0.413^{* * *}$ & 1.000 & & & \\
\hline ELoC1 & 0.022 & $0.143^{* *}$ & 0.082 & $0.191^{* * *}$ & $0.147^{* *}$ & 1.000 & & \\
\hline ELoC2 & 0.046 & $0.208^{* * *}$ & $0.119 * *$ & $0.253^{* * *}$ & $0.184^{* * *}$ & $0.575^{* * *}$ & 1.000 & \\
\hline ELoC3 & $0.119^{* *}$ & $0.216^{* * *}$ & 0.066 & $0.225^{* * *}$ & $0.230^{* * *}$ & $0.498^{* * *}$ & $0.612 * * *$ & 1.000 \\
\hline
\end{tabular}


With the removal of the "I'm touchy (ES1, N1)" and "I'm stubborn (ES3, N3)" items, GFI = 0.956, $\mathrm{CFI}=0.961$, and NNFI $=0.945$ were obtained for $\mathrm{H} 1$ to $\mathrm{H} 3$, respectively, all exceeding the cutoff of 0.9. Furthermore, the RMSEA was recorded as 0.070 , which was below the cutoff of 0.080 , and the normed chi-square reached 106.72 (exceeding 3). The model GFI was reestablished for hypotheses H4 to H6, and the GFI, CFI, and NNFI reached 0.972, 0.976, and 0.966, respectively (all > 0.9); the RMSEA was $0.048(<0.080)$; and the normed chi-square was $66.22(>3)$. The respective indices satisfied the requirements for goodness of fit. Therefore, these two proposed models were adopted as the final models in this study.

The path coefficient from emotional stability to internal locus of control (H1) was $0.44(t=7.421$, $p<0.001 ; \mathrm{SE}=0.060)$. The path coefficient from internal locus of control to PEB $(\mathrm{H} 2)$ was $0.31(t=5.003$, $p<0.001 ; \mathrm{SE}=0.063)$. The path coefficient from emotional stability to pro-environmental behavior $(\mathrm{H} 3)$ was $-0.02(t=-0.326, p>0.001 ; \mathrm{SE}=0.066)$. The path coefficient from neuroticism to external locus of control (H4) was $0.44(t=6.740, p<0.001 ; \mathrm{SE}=0.066)$. The path coefficient from external locus of control to PEB $(\mathrm{H} 5)$ was $-0.28(t=4.023, p<0.001 ; \mathrm{SE}=0.069)$. The path coefficient from emotional stability to pro-environmental behavior (H6) was $0.00(t=0.066, p>0.001$; $\mathrm{SE}=0.072)$.

Hence, H1, H2, and $\mathrm{H} 4$ were confirmed with moderately positive effects of $<0.3$. However, although $\mathrm{H} 4$ achieved significance, it exhibited a negative correlation and did not conform to the positive effect hypothesis; thus, H4 was not confirmed. H3 and H6 hypotheses were nonsignificant, and were thus not confirmed. The results of hypothesis testing are presented in Table 11. The final model of this study is as shown in Figures 3 and 4.

Table 11. Hypothesis verification.

\begin{tabular}{llll}
\hline & & \multicolumn{1}{c}{ Hypothesis } & Significance \\
\hline H1 & Emotional stability positively influences internal locus of control. & $* * *$ & Verification \\
H2 & Internal locus of control positively influences pro-environmental behavior. & $* * *$ & Established \\
H3 & Emotional stability positively influences pro-environmental behavior. & - & Established \\
H4 & Neuroticism positively influences external locus of control. & $* * *$ & Not established \\
H5 & External locus of control positively influences pro-environmental behavior. & $* * *$ & Established \\
H6 & Neuroticism positively influences pro-environmental behavior. & - & Not established (negative) \\
\hline
\end{tabular}

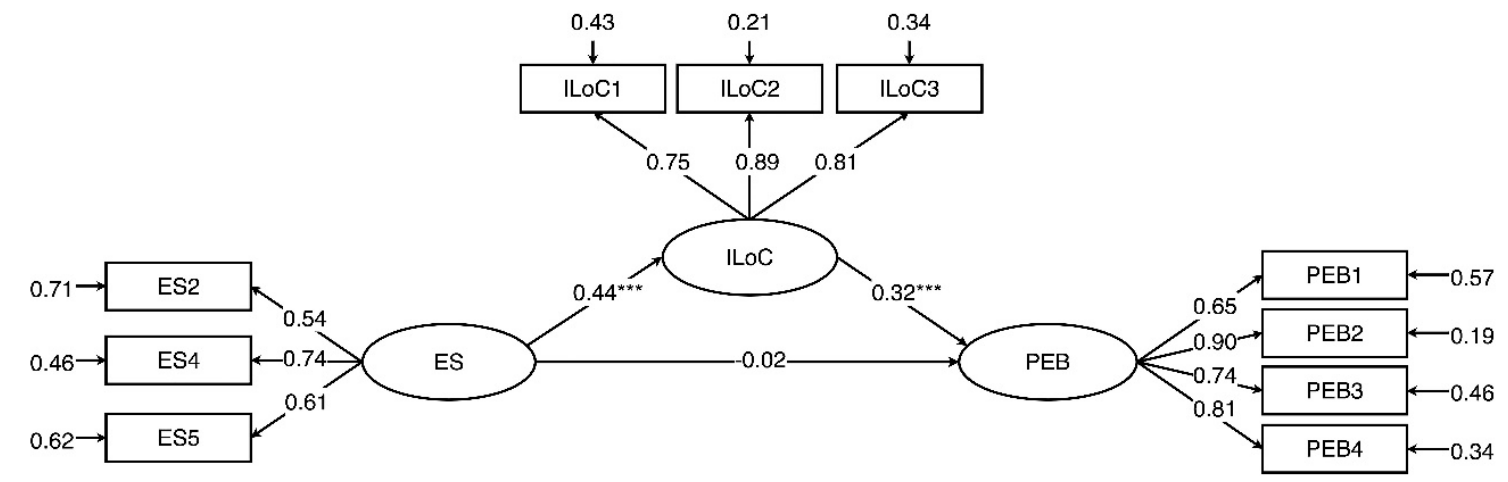

Chi-Square $=106.72, \mathrm{df}=32, \mathrm{P}$-value $=0.00000, \mathrm{RMSEA}=0.070$

Figure 3. Diagram of structural equation modeling (SEM) results for internal local control (ILoC), emotional stability (ES), and pro-environmental behavior (PEB). 


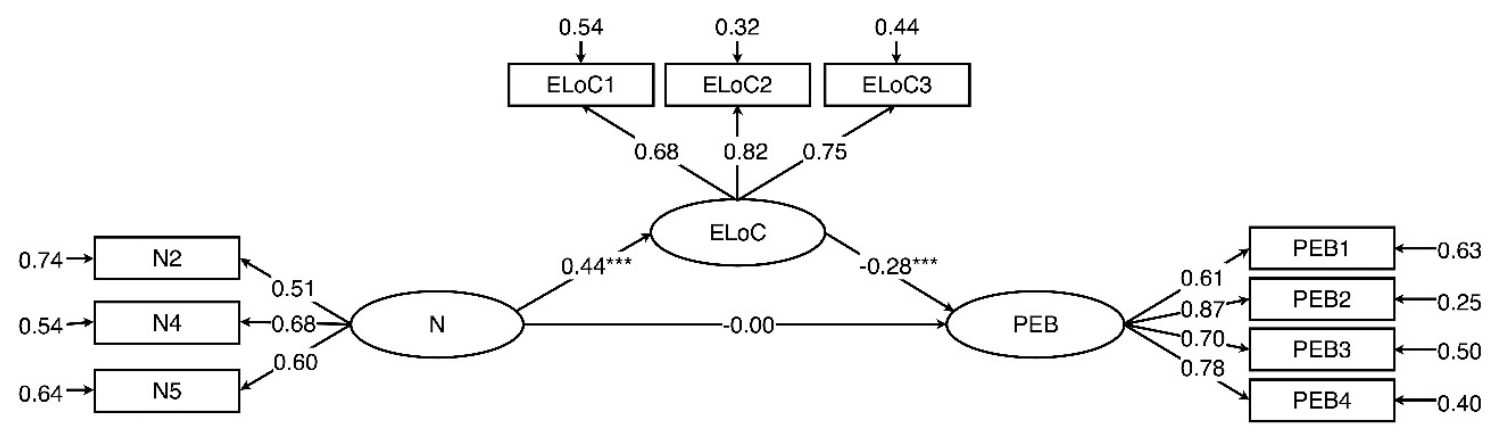

Chi-Square=66.22, $\mathrm{df}=32, \mathrm{P}$-value $=0.00035, \mathrm{RMSEA}=0.048$

Figure 4. Diagram of SEM results for external local control (ELoC), neuroticism (N), and pro-environmental behavior (PEB).

\section{Discussion}

In this study, we have investigated the relationships between the key variables (1) internal locus of control, emotional stability, and pro-environmental behavior and (2) external locus of control, neuroticism, and pro-environmental behavior. In particular, we aimed to identify the effects of emotional stability and neuroticism on pro-environmental behavior, the evidence of which had appeared in the extant literatures to be limited and inconclusive. This study aimed to fill this gap and provide further insights towards better understanding about the impact of emotional stability and neuroticism on pro-environmental behavior. The findings from the SEM analysis revealed the support and accepted three of the six hypotheses (i.e., H1, H2, and H4) proposed, suggesting significant positive direct relationships in this study.

Results suggested that "H1: emotional stability positively influences locus of control", and this aligned with related theories of emotional stability and locus of control [27-29]. This could be explained by individuals who had a high degree of emotional stability that could be more likely to possess distinctive characteristics such as patience, self-contentment, deliberateness, strength of mind, and objectivity [35-37], which play an important role in promoting internal locus of control.

Findings also revealed that internal locus of control positively influences pro-environmental behavior (H2). This was supported by previous studies [2-14], which had been conducted regarding the influence of locus of control on pro-environmental behavior. A possible explanation to this could be that people believed they had the capabilities to determine and control their actions. Therefore, persistent hard work, playing an important role in order to achieve success, could be achieved corresponding results of prosocial behaviors (i.e., exhibiting pro-environmental behavior) [20].

This study also confirmed that neuroticism positively influences external locus of control (H4), which was consistent with previous findings about anxiety influences external locus of control [30,31]. A high scorer in neuroticism on a personality test preformed emotionally reactive and behaved personal characteristics such as sensitivity, patience, impulsivity, irritability, nervousness, suspicion, self-pity, insecurity, worry [35-37], self-doubt [47], and pessimism [48]. The influence of external locus of control tends to be more evident when a person's emotional uneasiness increases [50].

In contrast, three hypotheses (i.e., H3, H5, and H6) had been rejected in this study. Firstly, while emotional stability was regarded as a key factor in the big five personality traits of pro-environmental behavior [39-44], the findings in this study did not uncover any positive relationship between emotional stability and pro-environmental behavior (H3). Instead, emotional stability could influence pro-environmental behavior through internal locus of control. Locus of control represented the mediation effect between emotional stability and pro-environmental behavior.

Results indicated that a positive relationship between external locus of control and pro-environmental behavior (H5) was not established, suggesting a negative impact occurred. 
This could be explained in the following manner: individuals who did not believe that their actions could make a difference to minimize the negative impact on the nature were unlikely to exhibit pro-environmental behavior [21]. This was also supported by previous studies [1] on individuals making no attempt to change or promote an outcome toward their expected direction. The direction of effects seen in "without change" condition mirrored that of the negative impact reflection condition, suggesting a "not willing to do" effect for possible cause of their psychological reflection.

"H6: neuroticism positively influences pro-environmental behavior" was rejected in this study. We rejected $\mathrm{H} 6$ and accepted the alternative hypothesis (H3): Emotional stability positively influences pro-environmental behavior [39-44]. Although previous studies had indicated that people were represented pro-environmental behavior while they are high on the neuroticism dimension [43,52,59], neuroticism and pro-environmental behavior exhibited no direct correlation in this study.

\section{Implications, Limitations, and Future Research}

SEM analysis confirmed that emotional stability influences pro-environmental behavior with internal locus of control as the mediator. When internal locus of control served as the mediating variable, emotional stability had no significant impact on pro-environmental behavior. Therefore, emotional stability was a predisposing factor for the path between internal locus of control and pro-environmental behavior.

Because emotional stability was a more easily observed explicit personality traits of locus of control, it could be used to reflect the key dimensions of the less easily observed locus of control. Thus, when a person is patient and strong-minded and displayed other characteristics of high emotional stability, this person might possess a greater level of internal locus of control. According to Peyton and Miller [1], such individuals might actively attempt to control their environment, search for knowledge and information to resolve environmental issues, and attempt to undertake pro-environmental behavior.

On the other hand, when a person is sensitive, impatient, impulsive, emotional, and pessimistic, or had a high level of neuroticism, this person is more likely to be affected by external locus of control, and thus fail to attempt to make changes or promote an outcome toward exhibiting pro-environmental behavior. Therefore, environmental educators and protection groups should focus special attention to the locus of control of people.

In addition, Peyton and Miller [1] claimed that locus of control was easy to change. To enhance locus of control for pro-environmental behavior, they proposed approaches including the use of positive and negative feedback during teaching and decision-making processes and improving students' self-image and their confidence in their ability to solve problems. Rotter, who first proposed the locus of control framework, also noted that individuals' feelings toward internal and external incentives and satisfaction reinforce certain behaviors, thus forming their locus of control [18].

This study revealed that if more consideration was given to the impact of emotional stability on locus of control, the internal locus of control could be effectively promoted during environmental education and protection actions, thus encouraging pro-environmental behavior at the personal level.

This study was conducted in Taiwan and cannot be generalized to the population at large and other settings. Studies in other regions could further expand the research results and strengthen regional research differentiation. Furthermore, previous studies had also supported the correlations between emotional stability and environmental values [43], neuroticism and environmental awareness, expectations for future environmental conditions, and environmental attitude [52]. These studies had indicated that the emotional stability-induced pro-environmental behavior pathway might include mediator variables other than locus of control. For future research, an alternative and inclusive approach may be beneficial. For example, a single research question may represent two different hypotheses that are currently contradictory to each other. Further in-depth investigation and discussion of these mediator variables and other influencing factors (i.e., other personality traits) are also warranted. 
Author Contributions: W.-T.F. and Y.-T.C. conceived and designed the experiments; Y.-T.C. performed the experiments; Y.-T.C. and W.-T.F. analyzed the data; W.-T.F., E.N., U.K, and Y.-T.C. contributed analysis tools; W.-T.F., Y.-T.C., U.K, and E.N. wrote the paper.

Funding: The authors disclosed receipt of the following financial support for the research, authorship, and publication of this article. The grants that we have received in support of our research work. We received funds for covering the costs to publish in open access. Preparation of this manuscript was supported by Grant MOST 105-2511-S-003-021-MY3 to W.-T. Fang from the Ministry of Science and Technology, Taiwan, ROC. This article was also subsidized by the National Taiwan Normal University (NTNU), Taiwan, ROC.

Conflicts of Interest: The authors declare no conflicts of interest.

\section{References}

1. Peyton, R.B.; Miller, B.A. Developing an internal locus of control as a prerequisite to environmental action taking. Curr. Issues VI 1980, 400, 193.

2. Hines, J.M.; Hungerford, H.R.; Tomera, A.N. Analysis and synthesis of research on responsible environmental behavior: A meta-analysis. J. Environ. Educ. 1987, 18, 1-8. [CrossRef]

3. Hwang, Y.-H.; Kim, S.-I.; Jeng, J.-M. Examining the causal relationships among selected antecedents of responsible environmental behavior. J. Environ. Educ. 2000, 31, 19-25. [CrossRef]

4. McCarty, J.A.; Shrum, L.J. The influence of individualism, collectivism, and locus of control on environmental beliefs and behavior. J. Public Policy Mark. 2001, 20, 93-104. [CrossRef]

5. Newhouse, N. Implications of attitude and behavior research for environmental conservation. J. Environ. Educ. 1990, 22, 26-32. [CrossRef]

6. Alp, E.; Ertepinar, H.; Tekkaya, C.; Yilmaz, A. A survey on turkish elementary school students' environmental friendly behaviours and associated variables. Environ. Educ. Res. 2008, 14, 129-143. [CrossRef]

7. Schwepker, C.H.; Cornwell, T.B. An examination of ecologically concerned consumers and their intention to purchase ecologically packaged products. J. Public Policy Mark. 1991, 10, 77-101. [CrossRef]

8. Allen, J.B.; Ferrand, J.L. Environmental locus of control, sympathy, and proenvironmental behavior. Environ. Behav. 1999, 31, 338-353. [CrossRef]

9. Balderjahn, I. Personality variables and environmental attitudes as predictors of ecologically responsible consumption patterns. J. Bus. Res. 1988, 17, 51-56. [CrossRef]

10. Shrum, L.J.; Lowrey, T.M.; McCarty, J.A. Recycling as a marketing problem: A framework for strategy development. Psychol. Mark. 1994, 11, 393-416. [CrossRef]

11. Ando, K.; Ohnuma, S.; Blöbaum, A.; Matthies, E.; Sugiura, J. Determinants of individual and collective pro-environmental behaviors: Comparing Germany and Japan. J. Environ. Inf. Sci. 2010, 38, 21-32.

12. Fielding, K.S.; Head, B.W. Determinants of young australians' environmental actions: The role of responsibility attributions, locus of control, knowledge and attitudes. Environ. Educ. Res. 2012, 18, 171-186. [CrossRef]

13. Abrahamse, W.; Steg, L.; Gifford, R.; Vlek, C. Factors influencing car use for commuting and the intention to reduce it: A question of self-interest or morality? Transp. Res. Part F Traffic Psychol. Behav. 2009, 12, 317-324. [CrossRef]

14. Jonsson, A.K.E.; Nilsson, A. Exploring the relationship between values and pro-environmental behaviour: The influence of locus of control. Environ. Values 2014, 23, 297-314. [CrossRef]

15. Geller, E.S. Actively caring for the environment. Environ. Behav. 1995, 27, 184-195. [CrossRef]

16. Fransson, N.; Gärling, T. Environmental concern: Conceptual definitions, measurement methods, and research findings. J. Environ. Psychol. 1999, 19, 369-382. [CrossRef]

17. Trigg, L.J.; Perlman, D.; Perry, R.P.; Janisse, M.P. Anti-pollution behavior. Environ. Behav. 1976, 8, $307-313$. [CrossRef]

18. Rotter, J.B. Social Learning and Clinical Psychology; Prentice-Hall, Inc.: Englewood Cliffs, NJ, USA, 1954; 466p.

19. Di Fabio, A.; Saklofske, D.H. Positive relational management for sustainable development: Beyond personality traits-The contribution of emotional intelligence. Sustainability 2019, 11, 330. [CrossRef]

20. April, K.A.; Dharani, B.; Peters, K. Impact of locus of control expectancy on level of well-being. Rev. Eur. Stud. 2012, 4, 124. [CrossRef]

21. Jacobs-Lawson, J.M.; Waddell, E.L.; Webb, A.K. Predictors of health locus of control in older adults. Curr. Psychol. 2011, 30, 173. [CrossRef] 
22. Carlson, N.R.; Heth, D.; Miller, H.; Donahoe, J.; Martin, G.N. Psychology: The Science of Behavior; Pearson: Harlow, UK, 2009.

23. Smith, T.W. The Book of Human Emotions: An Encyclopedia of Feeling from Anger to Wanderlust; Profile Books: London, UK, 2015.

24. Serebryakova, T.Y.A.; Morozova, L.B.; Kochneva, E.M.; Zharova, D.V.; Kostyleva, E.A.; Kolarkova, O.G. Emotional stability as a condition of students' adaptation to studying in a higher educational institution. Int. J. Environ. Sci. Educ. 2016, 11, 7486-7494.

25. Mount, M.K.; Barrick, M.R.; Stewart, G.L. Five-factor model of personality and performance in jobs involving interpersonal interactions. Hum. Perform. 1998, 11, 145-165. [CrossRef]

26. Kirkpatick, S.A.; Locke, E.A. Leadership: Do traits matter? Acad. Manag. Perspect. 1991, 5, 48-60. [CrossRef]

27. Morrison, K.A. Personality correlates of the five-factor model for a sample of business owners/managers: Associations with scores on self-monitoring, type a behavior, locus of control, and subjective well-being. Psychol. Rep. 1997, 80, 255-272. [CrossRef] [PubMed]

28. Morelli, G.; Krotinger, H.; Moore, S. Neuroticism and levenson's locus of control scale. Psychol. Rep. 1979, 44, $153-154$. [CrossRef] [PubMed]

29. Judge, T.A.; Erez, A.; Bono, J.E.; Thoresen, C.J. Are measures of self-esteem, neuroticism, locus of control, and generalized self-efficacy indicators of a common core construct? J. Personal. Soc. Psychol. 2002, 83, 693-710. [CrossRef]

30. Joe, V.C. Review of the internal-external control construct as a personality variable. Psychol. Rep. 1971, 28, 619-640. [CrossRef] [PubMed]

31. Ray, W.J.; Katahn, M. Relation of anxiety to locus of control. Psychol. Rep. 1968, 23, 1196. [CrossRef]

32. Archer, R.P. Relationships between locus of control, trait anxiety, and state anxiety: An interactionist perspective1. J. Personal. 1979, 47, 305-316. [CrossRef]

33. Watson, D.; Clark, L.A. Negative affectivity: The disposition to experience aversive emotional states. Psychol. Bull. 1984, 96, 465-490. [CrossRef]

34. Di Fabio, A.; Palazzeschi, L.; Bucci, O.; Guazzini, A.; Burgassi, C.; Pesce, E. Personality traits and positive resources of workers for sustainable development: Is emotional intelligence a mediator for optimism and hope? Sustainability 2018, 10, 3422. [CrossRef]

35. McCrae, R.R.; Costa, P.T. Validation of the five-factor model of personality across instruments and observers. J. Personal. Soc. Psychol. 1987, 52, 81-90. [CrossRef]

36. Saucier, G. Mini-markers: A brief version of goldberg's unipolar big-five markers. J. Personal. Assess. 1994, 63, 506-516. [CrossRef]

37. Roccas, S.; Sagiv, L.; Schwartz, S.H.; Knafo, A. The big five personality factors and personal values. Personal. Soc. Psychol. Bull. 2002, 28, 789-801. [CrossRef]

38. Parks-Leduc, L.; Feldman, G.; Bardi, A. Personality traits and personal values. Personal. Soc. Psychol. Rev. 2014, 19, 3-29. [CrossRef] [PubMed]

39. Gifford, R.; Nilsson, A. Personal and social factors that influence pro-environmental concern and behaviour: A review. Int. J. Psychol. 2014, 49, 141-157. [CrossRef] [PubMed]

40. Abdollahi, A.; Mobarakeh, M.R.V.; Karbalaei, S. Locus of control, hardiness, and emotional intelligence as predictors of waste prevention behaviours. Rom. J. Appl. Psychol. 2015, 17, 8-16.

41. Fraj, E.; Martinez, E. Influence of personality on ecological consumer behaviour. J. Consum. Behav. 2006, 5, 167-181. [CrossRef]

42. Swami, V.; Chamorro-Premuzic, T.; Snelgar, R.; Furnham, A. Personality, individual differences, and demographic antecedents of self-reported household waste management behaviours. J. Environ. Psychol. 2011, 31, 21-26. [CrossRef]

43. Milfont, T.L.; Sibley, C.G. The big five personality traits and environmental engagement: Associations at the individual and societal level. J. Environ. Psychol. 2012, 32, 187-195. [CrossRef]

44. Brick, C.; Lewis, G.J. Unearthing the "green" personality. Environ. Behav. 2014, 48, 635-658. [CrossRef]

45. Goldberg, L.R.; Sweeney, D.; Merenda, P.F.; Hughes, J.E., Jr. Demographic variables and personality: The effects of gender, age, education, and ethnic/racial status on self-descriptions of personality attributes. Personal. Individ. Differ. 1998, 24, 393-403. [CrossRef]

46. Byrom, N.C.; Murphy, R.A. It's not just what we encode, but how we encode it: Associations between neuroticism and learning. J. Personal. 2013, 81, 345-354. [CrossRef] [PubMed] 
47. Komarraju, M.; Karau, S.J.; Schmeck, R.R.; Avdic, A. The big five personality traits, learning styles, and academic achievement. Personal. Individ. Differ. 2011, 51, 472-477. [CrossRef]

48. Zhang, L.-F. Thinking styles and the big five personality traits. Educ. Psychol. 2002, 22, 17-31. [CrossRef]

49. Wiseman, M.; Bogner, F.X. A higher-order model of ecological values and its relationship to personality. Personal. Individ. Differ. 2003, 34, 783-794. [CrossRef]

50. Van Egeren, L.F. A cybernetic model of global personality traits. Personal. Soc. Psychol. Rev. 2009, 13, 92-108. [CrossRef]

51. Hirsh, J.B. Personality and environmental concern. J. Environ. Psychol. 2010, 30, 245-248. [CrossRef]

52. Liem, G.A.D.; Martin, A.J. Young people's responses to environmental issues: Exploring the roles of adaptability and personality. Personal. Individ. Differ. 2015, 79, 91-97. [CrossRef]

53. Castiglioni, C.; Lozza, E.; Bonanomi, A. The Common Good Provision Scale (CGP): A Tool for assessing people's orientation towards economic and social sustainability. Sustainability 2019, 11, 370. [CrossRef]

54. Pourhoseinzadeh, M.; Gheibizadeh, M.; Moradikalboland, M. The Relationship between Health Locus of Control and Health Behaviors in Emergency Medicine Personnel. Int. J. Community Based Nurs. Midwifery 2017, 5, 397-407.

55. Kalamas, M.; Cleveland, M.; Laroche, M. Pro-environmental behaviors for thee but not for me: Green giants, green Gods, and external environmental locus of control. J. Bus. Res. 2014, 67, 12-22. [CrossRef]

56. Cleveland, M.; Kalamas, M.; Laroche, M. "It's not easy being green": Exploring green creeds, green deeds, and internal environmental locus of control. Psychol. Mark. 2012, 29, 293-305. [CrossRef]

57. Blanchard, A.L.; Henle, C.A. Correlates of different forms of cyberloafing: The role of norms and external locus of control. Comput. Hum. Behav. 2008, 24, 1067-1084. [CrossRef]

58. Spokas, M.; Heimberg, R.G. Overprotective parenting, social anxiety, and external locus of control: Cross-sectional and longitudinal relationships. Cogn. Ther. Res. 2009, 33, 543-551. [CrossRef]

59. Kvasova, O. The big five personality traits as antecedents of eco-friendly tourist behavior. Personal. Individ. Differ. 2015, 83, 111-116. [CrossRef]

60. Goldberg, L.R. The development of markers for the big-five factor structure. Psychol. Assess. 1992, 4, $26-42$. [CrossRef]

61. UNEP. The belgrade charter. In Proceedings of the International Workshop on Environmental Education, Belgrade, Serbia, 13-22 October 1975. ED-76/WS/95.

62. Hungerford, H.R. Investigating and Evaluating Environmental Issues and Actions: Skill Development Modules. A Curriculum Development Project Designed to Teach Students How to Investigate and Evaluate Science-Related Social Issues. Modules I-VI; ERIC: Columbus, OH, USA, 1985.

63. Jöreskog, K.G.; Sörbom, D. Lisrel 9.20 for Windows [Computer Software]; Scientific Software International, Inc.: Skokie, IL, USA, 2015.

64. Hair, J.; Black, W.; Babin, B.; Anderson, R. Multivariate Data Analysis, 7th ed.; Pearson: Harlow, UK, 2009. 